\title{
Use of Computerized Clinical Decision Support for Diagnostic Stewardship in Clostridioides difficile testing: an Academic Hospital Quasi-Experimental Study
}

\author{
Anne E. Friedland, $M D^{7}$, Sara Brown, $M D^{7}$, Danielle R. Glick, $M D^{7}$, Martha C. Lusby, RN, BSN ${ }^{7}$, \\ Daniel Lemkin, $M D^{2}$, and Surbhi Leekha, MBBS, MPH²
}

'University of Maryland Medical Center, Baltimore, MD, USA; ${ }^{2}$ University of Maryland School of Medicine, Baltimore, MD, USA.

KEY WORDS: diagnostic stewardship; overdiagnosis; Clostridium difficile; clinical decision support.

J Gen Intern Med 34(1):31-2

DOI: $10.1007 / \mathrm{s} 11606-018-4659-4$

(c) Society of General Internal Medicine 2018

\section{INTRODUCTION}

Overdiagnosis of Clostridioides difficile as a cause of healthcare-associated diarrhea is a prevalent problem in the USA due to increasing use of highly sensitive nucleic acid amplification tests, combined with a low threshold for testing of patients in the absence of significant diarrhea and in the presence of laxatives. ${ }^{1-3}$ Others have reported on efforts at reducing unnecessary $C$. difficile testing through computerized clinical decision support (CCDS), with variable results. ${ }^{4,5} \mathrm{We}$ conducted a quasi-experimental study to evaluate the impact of CCDS on appropriateness of $C$. difficile testing.

\section{METHODS}

This study was part of a quality improvement project at our 750-bed tertiary-care academic hospital, and was determined to be non-human subjects research by the University of Maryland IRB. Among consecutive hospitalized patients undergoing $C$. difficile testing from $2 / 19 / 16$ to $3 / 19 / 16$, charts were reviewed for presence of clinically significant diarrhea (i.e., $\geq$ 3 loose stools in $24 \mathrm{~h}$, or any loose stool with abdominal cramps), laxative use in preceding $48 \mathrm{~h}$, whether an indication for testing was documented, whether testing was done as part of a "sepsis panel," and prior $C$. difficile testing (and result) in the same admission. Testing was considered indicated if the patient had clinically significant diarrhea in the absence of recent laxative use or had ileus. In December 2016, four alerts based on diarrhea documentation, laxative use, and prior C. difficile tests were placed into the electronic medical record notifying clinicians of potentially unnecessary testing and allowing the opportunity to delete the order. Education and rationale for these alerts were disseminated electronically. Post-intervention data were collected on $C$. difficile orders from $1 / 21 / 17$ to $2 / 19 / 17$. Chi-square test was used to compare

Published online September 14, 2018 patient characteristics before and after implementation; $p<0.05$ was considered significant.

\section{RESULTS}

The pre-intervention group had 280 patients, of which 35 (13\%) were positive. Post-intervention group had 167 patients, of which $18(11 \%)$ were positive. Comparing post- to preintervention, patients undergoing $C$. difficile testing were more likely to have significant diarrhea ( $75 \%$ vs. $60 \%, p=0.003$ ) and a documented indication for testing (79\% vs. $67 \%, p=$ 0.003 ), and less likely to have laxative use in the preceding $48 \mathrm{~h}$ ( $37 \%$ vs. $46 \%, p=0.03)$, or repeat testing during the same admission ( $26 \%$ vs. $31 \%, p=0.2$.) Testing was frequently done as part of sepsis evaluation and was unchanged postintervention (33\% vs. $32 \%$ ). Overall, testing was considered clinically indicated in 53\% post-intervention compared to $40 \%$ pre-intervention $(p=0.004)$.This difference was not statistically significant among only those with positive tests (Table 1).

\section{DISCUSSION}

A CCDS-based intervention led to statistically significant decreases in inappropriate $C$. difficile testing but constituted marginal clinical quality improvement $(\sim 13 \%$ in overall appropriate testing). Moreover, nearly $40 \%$ of patients reviewed post-intervention had laxative use in the preceding $48 \mathrm{~h}$, and a third underwent testing as part of a broad sepsis evaluation. These results mirror those at another academic hospital system with statistically but not clinically significant reductions in C. difficile tests associated with laxative use, and no improvement in $C$. difficile rates with use of CCDS. ${ }^{4}$ In contrast, others have reported significant reductions in inappropriate C. difficile testing using a "hard stop" intervention, ${ }^{6}$ and by coupling education with financial incentives. ${ }^{5}$ In review of alert usage (data not presented), we found that alerts were frequently ignored/dismissed, and anecdotally, frontline clinicians held strong beliefs about $C$. difficile testing similar to that observed elsewhere. ${ }^{3}$ 
Table 1 Characteristics Associated with $C$. difficile Testing Before and After Computerized Clinical Decision Support, University of Maryland Medical Center, 2016-2017

\begin{tabular}{llll}
\hline \hline & $\begin{array}{l}\text { Pre- } \\
\text { intervention } \\
(\boldsymbol{n}=\mathbf{2 8 0})^{*}\end{array}$ & $\begin{array}{l}\text { Post- } \\
\text { intervention } \\
(\boldsymbol{n}=\mathbf{2 3 9})^{*}\end{array}$ & $\begin{array}{l}\text { Chi- } \\
\text { square, } \\
\boldsymbol{p} \text { value }\end{array}$ \\
\hline $\begin{array}{l}\text { Positive C. difficile } \\
\text { test }\end{array}$ & $35(13 \%)$ & $26(11 \%)$ & - \\
$\geq 3$ loose stools per & $157(60 \%)$ & $164(69 \%)$ & 0.04 \\
$\begin{array}{l}\text { day } \\
\begin{array}{l}\text { Any loose stool plus } \\
\text { abdominal cramping }\end{array}\end{array}$ & $47(43 \%)$ & $62(57 \%)$ & 0.02 \\
$\begin{array}{l}\text { Clinically } \\
\text { significant diarrhea }\end{array}$ & $168(60 \%)$ & $179(75 \%)$ & 0.04 \\
$\begin{array}{l}\text { Testing done as part } \\
\text { of "sepsis panel" }\end{array}$ & $87(32 \%)$ & $80(33 \%)$ & 0.74 \\
$\begin{array}{l}\text { Documented } \\
\text { indication for testing }\end{array}$ & $188(67 \%)$ & $188(79 \%)$ & 0.003 \\
$\begin{array}{l}\text { Laxative use in } \\
\text { preceding 48 h }\end{array}$ & $127(46 \%)$ & $88(37 \%)$ & 0.03 \\
$\begin{array}{l}\text { Repeat testing in } \\
\text { same admission } \\
\text { Testing clinically } \\
\text { indicated (all } \\
\text { patients) }\end{array}$ & $86(31 \%)$ & $60(26 \%)$ & 0.20 \\
$\begin{array}{l}\text { Testing clinically } \\
\text { indicated } \text { (patients } \\
\text { with positive tests) }\end{array}$ & $18(53 \%)$ & $18(69 \%)$ & 0.20 \\
\hline
\end{tabular}

*Consecutive patients undergoing $C$. difficile testing reviewed from 2/19/16 to 3/19/16 (pre-intervention assessment period) and from 1/21/ 17 to 2/19/17 (post-intervention assessment period); denominators may be smaller than the column total due to missing data for some variables ${ }^{b}$ Testing clinically indicated patient with ileus or patient with 3 loose stools/day or any loose stool with abdominal cramps, in the absence of laxative

Strengths of this study include an in-depth evaluation of appropriateness of testing before and after the intervention. Weaknesses include a single academic center study with small sample size, which did not allow an adequately powered analysis of impact on false positive $C$. difficile cases. A weakness of the intervention itself is the possibility of alert fatigue with CCDS. These findings underscore the importance of arming frontline clinicians with appropriate tools on diagnostic testing, and emphasize the potentially low utility of "soft stops" or alerts in this setting. Indeed, at our hospital, these results led to petitioning for a "hard stop" or cancelation of the order when meeting criteria for unnecessary testing.

In summary, a CCDS-based intervention had limited utility in improving appropriateness of $C$. difficile testing in this single-center study. Additional strategies and qualitative studies of clinicians' decision-making are necessary to improve diagnostic stewardship for this pathogen.

Corresponding Author: Surbhi Leekha, MBBS, MPH; University of Maryland School of Medicine, 110 S. Paca St, Baltimore, MD 21201, USA (e-mail: sleekha@som.umaryland.edu).

\section{Compliance with Ethical Standards:}

Conflict of Interest: The authors declare no conflicts of interest.

\section{REFERENCES}

1. Rock C, Pana Z, Leekha S, Trexler P, Andonian J, Gadala A, Carroll KC, and Maragakis LL; CDC Prevention Epicenters Program. National Healthcare Safety Network laboratory-identified Clostridium difficile event reporting: a need for diagnostic stewardship. Am $J$ Infect Control. 2018;46:456-458.

2. Kelly SG, Yarrington M, Zembower TR, Sutton SH, Silkaitis C, Postelnick M, Mikolajczak A and Bolon MK. Inappropriate Clostridium difficile Testing and Consequent Overtreatment and Inaccurate Publicly Reported Metrics. Infect Control Hosp Epidemiol. 2016;37:1395-1400.

3. Kinlay $\mathbf{J}$ and Sandora $\mathbf{T} \mathbf{J}$. A qualitative study to identify reasons for Clostridium difficile testing in pediatric inpatients receiving laxatives or stool softeners. Am J Infect Control. 2017;45:539-541.

4. White DR, Hamilton KW, Pegues DA, Hanish A and Umscheid CA. The Impact of a Computerized Clinical Decision Support Tool on Inappropriate Clostridium difficile Testing. Infect Control Hosp Epidemiol. 2017;38:12041208.

5. Madden GR, German Mesner I, Cox HL, Mathers AJ, Lyman JA, Sifri CD and Enfield KB. Reduced Clostridium difficile Tests and LaboratoryIdentified Events With a Computerized Clinical Decision Support Tool and Financial Incentive. Infect Control Hosp Epidemiol. 2018;39:737-740.

6. Rock C, Mizusawa M, Small B, Hsu Y, Kauffman C, Trivedi J, Landrum B, Feldman L, Pahwa A, Carroll KC and Maragakis LL. Implementation of Electronic Medical Record Hard Stop Alerts for Inappropriate Clostridium difficile Tests in Academic and Community Hospital Setting; Impact on Testing Rates and Clinical Outcomes. Open Forum Infect Dis. 2017;4 (Suppl 1):S608 